Article

\title{
Publicly-Researchable Accessibility Information: Problems, Prospects and Recommendations for Inclusion
}

\author{
Carol Kaufman-Scarborough \\ School of Business, Rutgers University-Camden, Camden, NJ 08102, USA; E-Mail: ckaufman@camden.rutgers.edu
}

Submitted: 28 June 2018 | Accepted: 25 September 2018 | Published: 31 January 2019

\begin{abstract}
Despite worldwide attempts to improve accessibility for consumers with disabilities, barriers still exist that exclude persons from consumer participation in daily life. Although legislation and lawsuits have addressed this issue, marketplaces designed for able-bodied persons are commonplace with minimal accessibility standards tied to costs rather than the needs of this overlooked group. The present article examines a seemingly obvious, but understudied aspect of inclusion: the provision of publicly-researchable accessibility information. Ironically, businesses and public venues may create accessible spaces, yet fail to provide the level of detail needed by consumers with disabilities when planning a shopping excursion, dinner and entertainment, or travel and overnight stays. That is, the provision of factual accessibility content has lagged and is not required by law. This article reports on an exploratory study in the United States that examined the accuracy and completeness of publicly-researchable accessibility information for restaurant and entertainment venues in a large metropolitan area in the Northeastern United States. Observations were gathered from websites and social media of specific venues, as well as travel rating services like TripAdvisor. Findings were mixed. While some venues provided full and factual accessibility information, others revealed just the opposite both in online and follow-up telephone interviews. Implications are discussed along with recommendations for future study.
\end{abstract}

\section{Keywords}

accessibility; consumer planning; disabilities; information; online

\section{Issue}

This article is part of the issue "People with Disabilities: The Overlooked Consumers", edited by Anita Borch and Kirsi Laitala (Consumption Research Norway-SIFO, Norway).

(C) 2019 by the author; licensee Cogitatio (Lisbon, Portugal). This article is licensed under a Creative Commons Attribution 4.0 International License (CC BY).

\section{Introduction}

Within the last several decades, worldwide attention has focused on providing equal rights for people with disabilities in all areas of life including employment, education, access to politics and justice, and full inclusion in cultural events, leisure and sports. One example of global collaborative effort is found in the Convention of the Rights of Persons with Disabilities (CRPD; United Nations, 2018). According to its website, the CRPD is an international disability treaty for creating legislation and policies around the world that embrace the rights and dignity of all people with disabilities. It reports using the Americans with Disabilities Act (ADA) as a model and applies many of the ADA's concepts within the treaty to build and strengthen the rights of persons with disabilities worldwide.
However, civil rights laws addressing the needs of persons with disabilities have offered a promise of inclusion that has not yet been fully realized. While built environments have increasingly added more accessibility features, accommodations can differ greatly from one location to another. Such differences are likely to prompt persons with disabilities to thoroughly prescreen the businesses that they patronize. Unfortunately, convenient and easy-to-use accessibility information can be difficult to locate either online or in person when needed. This article attempts to address this gap through an initial study of accessibility information sources.

Since there is no standard requirement for publicizing accessibility information for commercial businesses, consumers who want to prescreen businesses may find that description of facilities, parking, and other accom- 
modations vary substantially when viewed online or discussed with employees. When companies provide minimal or no training in addressing actual customers' accessibility needs, incomplete and incorrect information may be provided leading to unsatisfactory experiences and exclusion from parts of the consumer experience. Such an information gap raises an understudied problem in disabilities studies: the varied and often missing publiclyresearchable accessibility information.

This article reports on an exploratory study in the United States that addresses the question whether clear, correct, predictable, and personalized accessibility information is available from businesses patronized by consumers with disabilities. The study collected information posted online regarding a venue's accommodations, followed up by personal phone calls and visits. This manuscript also introduces the concept of "accessibility messaging", presents the findings, and offers recommendations for policy regarding the provision of information regarding public venue accessibility.

\section{Literature Review}

Throughout the last several decades, civil rights laws such as the 1990 ADA, the 2006 CRPD (United Nations), and the 2015 European Accessibility Act (European Commission) mandated that public places become accessible for all. Much progress has been made as increasing numbers of persons with disabilities have felt welcomed and included in public spaces (Baker, Holland, \& Kaufman-Scarborough, 2007). While mobility accommodations are increasingly part of new building designs, sign language usage, closed captioning, large print materials, and food allergy accommodations are also anticipated in the public marketplace. Considerable efforts have also been undertaken to design websites that are accessible to persons with disabilities, especially if screen-reading software such as JAWS for Windows are used (Kaufman-Scarborough \& Childers, 2009; Ritchie \& Blanck, 2003; Schaefer, 2003; WEBAIM, 2018).

\subsection{Disabilities and Inclusion}

As members of a group, organization, or society, people are thought to experience a set of identifiable basic needs: belongingness, self-esteem, control, and meaningful existence (Williams \& Nida, 2011). In order to meet those needs and attain life satisfaction, they may seek to be included, building relationships when they join and choose ways to become involved. Factors beyond their control may limit if, how, and whether they can be included. That is, they may be restricted from participation and excluded from part or all aspects of membership (Baumeister, DeWall, Ciarocco, \& Twenge, 2005; Wan, $\mathrm{Xu}, \&$ Ding, 2014). Exclusion can be experienced in many ways, such as simply not meeting criteria for membership like a minimum grade point average. It can also result from not meeting societal standards and expecta- tions regarding abilities to perform. Unfortunately, the results of failure to meet inclusion criteria can also include being ostracized, banned, or stigmatized based on collective norms and values of the members' cultural preferences or society.

The concepts of social inclusion and exclusion are foundational building blocks in disabilities studies. Built environments can become "enabling" or "disabling" based on a designer's understanding of accessibility, when they ignore it, or when they seek to exclude persons with disabilities. Workplaces and educational institutions can disable their employees and students when attention is not paid to accessible communications, mobility needs, and various sensory issues such as multiple chemical sensitivities (Vierstra, Rumrill, Koch, \& McMahon, 2007). When the marketplace is considered, store, mall, and online shopping designers may select options that enhance or limit accessibility when an ableist approach is adopted (Bromley \& Thomas, 1993; Davis, 2003).

\subsection{Disabilities Research and Models: Moving from Exclusion to Inclusion}

The public environment has come a long way from a prior focus on disabilities exclusion. Persons with disabilities had often lived separately from society as people to be avoided, feared, protected, and even institutionalized rather than being part of public life (Goffman, 1963). An accompanying language also developed as persons "became" their disabilities and assumed labels such as blind, deaf, lame, epileptic, and mute rather than simply being persons with disabilities.

Early disabilities scholars analyzed the experiences, care, and stigmas that persons with disabilities experienced as "Disabilities Studies" emerged as a multidisciplinary area of academic interest. The medical model and the social model had been predominant in past theoretical research (Chouinard, 1997; Imrie, 1999; Oliver, 1990; Shakespeare, 1993, 2013; Shakespeare \& Watson, 2001). More recently, a modern model has emerged called the affirmation model of disability (Swain \& French, 2000). Each model offers a unique lens based on how persons with disabilities are perceived in terms of their social identity, their experiences, and their inclusion in society. Each will be considered briefly.

The "medical model" assumed a society in which persons with disabilities are excluded and isolated (Llewellyn \& Hogan, 2000). It is rooted in "ableism", or an expectation that individuals who participate in society are typically able-bodied (Chouinard, 1997). Based on this perspective, the "built environment" would be constructed drawing on attributes of normalcy, requiring that persons with disabilities should either be "repaired" in some way or simply not participate in the activities of everyday life. This approach, which Swain and French (2000) term a "tragedy model", results in buildings and accompanying infrastructure whose designers did not an- 
ticipate the inclusion of persons with disabilities (Paar \& Butler, 1999).

A contrasting approach proposes that society itself may be at fault and can be fixed, amended, and constructed in new ways that attempt to include all persons. This "social model" focuses on common elements of the built environment that can become welcoming and open to all. Such an approach set the stage for civil rights laws guaranteeing accommodations in public spaces such as schools, shops, religious institutions, and entertainment venues. When goals of access become predominant, the built environment can be required to create spaces of inclusion where persons with disabilities can function comfortably and effectively (Oliver, 1990). As a result, persons with disabilities are perceived as expected participants in the marketplace seeking "consumer normalcy" by being included in regular marketplace transactions (Baker, 2006; Baker, Gentry, \& Rittenburg, 2005).

Finally, the affirmation model proposes that persons with disabilities are thought to celebrate their lives and view their disability through a positive lens. While building on the social model, this contrasting approach emphasizes individual value and identity, control of healthcare alternatives, and the positive experiences of persons with disabilities. This perspective of empowerment challenges one view of normality and instead considers persons with disabilities as participating in creating their own lifestyles, cultures, and identities (Swain \& French, 2000).

\subsection{Uneven Progress: Inclusion and Exclusion and the Exchange of Meaning}

While public policies, academic studies, and charitable efforts have attempted to ensure access in the marketplace, actual information about accessibility options such as large print menus, sign language, and ramps content does not appear to have been uniformly regulated nor presented in a standardized format worldwide. For instance, the ADA mandates accessibility in public marketplaces but does not apparently stipulate that businesses provide advance information about marketplace accessibility in their online, print, and interpersonal communications.

As one might expect, consumers with disabilities have a greater need for certainty and factual information regarding their abilities to plan activities in advance. They report consulting a variety of sources, such as a venue's own website, Facebook page, and other travel-related rating services such as TripAdvisor and Trivago yet report mixed results. Photos of attractive restaurants and hotels may be provided along with various activities in entertainment literature, yet significant information gaps are noted by public advocates who offer rating services (Disabled Foodie, 2016). Public spaces may state that they are "handicapped accessible" and post an accessibility icon on their media. However, the quality of information may fail to address the specific needs of potential patrons, such as seating with other patrons, recorded mes- saging, braille, hearing assistance, service animals, and other aspects of accessibility. Moreover, employees are found to vary considerably in their training and expertise in serving persons with disabilities (Baker et al., 2007).

\section{Problem Statement: Inclusive Information for Consumer Accessibility Evaluation and Choice}

Consumer decision-making theory tells us that individuals rely heavily on information in making market place decisions. That is, individuals may extract, process, and use information in selecting stores, making purchases, and patronizing service-based businesses (Bettman, 1979; Bettman, Luce, \& Payne, 1998; Johnson \& Levin, 1985). These studies provide evidence that when a specific need or requirement is very important to a consumer, they will spend additional time and effort in searching for needed information, processing it, and using that information to create a set of acceptable venues called a "consideration set". Such a decision process may prompt someone with mobility disabilities to pre-screen shopping venues for needed accommodations such as ramps, elevators, and handicapped parking. Consumer evaluation and choice, however, can be compromised when relevant information is missing. As a result, a consumer with disabilities may find themselves excluded since an accurate evaluation cannot be made.

\subsection{Accessibility Messaging}

This manuscript introduces a concept called "accessibility messaging", that refers to the information indicating the availability of accommodations provided by in the marketplace or by specific venues. For instance, stores, museums, or shopping malls might develop brochures and web sites that describe the mobility accessible entrances, the use of sign language interpreters, and the availability of large-print materials and recorded information. Universities might additionally provide information on closed captioning options, opportunities for notetakers, alternative test formats, and online materials prepared with transcripts and formats compatible with screen readers (Betts et al., 2013).

In addition, there has been a significant growth in information, reviews, and ratings posted by third-party sources such as city guides, hospitality services like Trip Advisor, Facebook, and Yelp, interest groups such as the Food Network and Open Table, and other web-based services such as Google. It is important to note that these third-party sources may collect partial or dated information, such as exterior photos from Google Maps or paid advertisements that selectively provide information to a limited set of venue characteristics.

\subsection{A Typology of Accessibility Messaging}

Ironically, accessible built environments can become "disabling" environments when their messaging fails 
to provide needed information causing their elimination from the consideration set for potential consumers. We anticipate that patterns of accessibility messaging can be analyzed using the following typology (KaufmanScarborough, 2015):

- Universal inclusion: A venue is accessible and consumer information provides a complete description of access;

- Unintended exclusion: A venue is accessible, but accessibility information is incomplete or difficult to obtain;

- Selective inclusion: A venue is partially accessible with a complete description of access;

- Rejected exclusion: A venue is not accessible and does not provide accessibility information.

This typology is based on the inclusion/exclusion dichotomy but recognizes that there may be differing degrees of access for persons with disabilities. In the first case, a venue is classified as having "universal inclusion" if it welcomes consumers with various types of abilities and disabilities, using the principles of universal design or design for everyone. Additionally, the venue attempts to provide thorough information or a way to obtain it, such as advising the consumer to reach out in advance. This is in contrast to "rejected exclusion", in which a venue appears to be designed based on ableism, effectively rejecting those who are not able-bodied. Moreover, accessibility information is ignored and a lack of welcome is communicated.

The remaining two classifications present a middleground in which inclusive design and/or accessibility information is not complete. The first, "unintended exclusion", attempts to specifically consider venues that offer accessible facilities but do not communicate it thoroughly. They are the primary focus on this study since it is their information that appears to deny inclusion or may cause consumers to exclude themselves. "Selective inclusion", on the other hand, refers to venues that have chosen specific disabilities to accommodate, perhaps in response to legal mandates, but they have ignored the needs of consumers with other disabilities. For instance, some venues have emphasized readily visible accommodations such as ramps, automatic doors, and elevators in addressing mobility needs, but may report not considering patronage by consumers with invisible disabilities such as hearing, vision, and neurological impairments.

\section{Methodology}

An exploratory study was conducted at a major University in the Northeastern United States in Fall 2016. Student observers in an upper-level undergraduate Retailing class collected observations of public accessibility messaging provided by businesses in a major metropolitan area. In preparation for the study, the student observers first read academic and practitioner articles illus- trating the information that consumers with disabilities reported as important when evaluating businesses to patronize. They next attended a training session providing insights into the anticipation, selection and identification of sources of accessibility information. They were asked to record their observations using a standard rubric and requested to focus on whether the information they collected would be sufficient for persons with disabilities to confidently patronize the venue.

The standard rubric was used by all student investigators. In addition to providing a detailed narrative of their findings, they were required to complete a standard table investigating accommodations for a minimum of five disabilities: mobility, vision, hearing, food allergies, and sensory. The table provided several accommodations drawn from the literature and practical writings on access such as ramps and automatic doors, bright lighting, sign language, gluten and peanut free, and perfume and smoke free. Students were asked to rate each area they discussion on a scale of 1 (worst) to 10 (best) on perceived accessibility.

The investigation in this study considers two type of "public accommodations", restaurants and entertainment venues that come under the jurisdiction of Title III of the ADA. A place of public accommodation is a facility whose operations affect commerce and falls into one or more of twelve specific categories defined by the government. Two of the twelve categories characterize this research: 1) places that serve food or drink (restaurants and bars), and 2) places of exhibition or entertainment (theaters, stadiums, arenas). For this study, disabilities access is measured against the ADA of 1990, the Standards of 1991, and the revised standards of 2010. They are described in detail in the ADA National Network Disability Law Handbook (Brennan, 2013).

\subsection{The Student Observer Scenario}

All student observers were asked to select one restaurant and one entertainment venue for evaluation based on the information provided online by the venues themselves and other third-party sources. They were also asked to make a confirmation phone call and/or visit to each selected venue to evaluate accommodations related to mobility, hearing, vision, sensory, and dietary impairments. To increase their involvement with the assignment, all student observers were given the scenario below:

Suppose you are a junior executive at a large multinational company. You have been assigned to host a team of five guests from another division of your company who have never been to [the local major city]. Your planned itinerary includes dinner at an upscale venue and an evening at a local entertainment venue such as a concert or a major league sports event. About a week before the visit, your manager stops by to alert you that at least one of your guests has 
a hearing impairment and another occasionally uses a wheelchair due to a mobility limitation. You quickly go online to check specific accessibility for the venues you are considering. You also check travel sources like TripAdvisor and Trivago for ratings and reviews. What level of detail should you expect to find to help you plan a successful visit by the team?

\subsection{Sample of Venues}

A total of 37 student observers participated in the study, each collecting data from one restaurant and one entertainment venue that they had chosen for the study. While 75 observations were submitted, the final sample of 52 venues were used in this analysis. The remaining observations were omitted due to overlap, duplication, or incomplete data. An overall total of 33 restaurants were analyzed in the final sample. They included global and national chains as well as small local venues. The 19 entertainment venues included a variety of formats, with the majority focusing on major sports facilities. Others were museums, libraries, and movie theaters.

\section{Analysis}

Ideally, all 52 venues would have indicated that their messaging indicated universal inclusion. However, the data revealed considerable variability across the venues although some patterns were identified. Some of the venues were found to excel in providing accommodations, while others were actually in violation of the ADA. For instance, venues were identified that denied access for service animals, failed to offer usable ramps and automatic doors, neglected to consider the importance of proper lighting for persons with visual impairments, and ignored the needs of persons with hearing impairments in communicating independently with employees.

\subsection{Evaluation of Observed Acceptable Outcomes}

First, the 11 large entertainment venues in the sample primarily included nationally-recognized museums and sports complexes. Each clearly excelled in extensive accommodations, providing supportive and knowledgeable staff plus detailed downloadable information. Since stadiums and convention centers are often prominent places of public accommodation, they are required to adhere to the comprehensive accommodations required by both national and potentially global standards. Additionally, public interest and third-sector organizations have also established detailed guides concerning stadium access for persons with disabilities. An example is found in Accessible Stadia (2003) available online by the Football Stadia Improvement Fund. Venues such as these clearly illustrate "universal inclusion".

One student observer made the following assessment of a prominent athletic facility in a major United States city:
After reviewing the information available on the website of Lincoln Financial Field, they seem to be very accommodating to all kinds of disabilities. They also have very detailed descriptions of all the rules and services provided, stating: "We welcome members of our disabled community to Lincoln Financial Field, which is fully compliant with the Americans with Disabilities Act".... Lincoln Financial Field has highly advanced, top of the line hearing assistance devices and also has Braille guides for the entire stadium located at all Guest Service booths.

\subsection{Evaluation of Observed Unacceptable Outcomes}

The remaining 41 eligible cases consisted of both large and small venues that did not provide full accessibility information and varied in the accommodations they discussed in publicly. Essentially, both unintended exclusion and selective inclusion overlapped since various combinations of partial accessibility and partial public information tended to be the most common finding. One common finding indicated that the majority typically indicated some information of mobility, ramps, and automatic doors in their promotional materials. Consumers with other disabilities and special dietary needs instead were asked to contact the venue for information and special assistance. Other venues appeared to downplay the effectiveness of their accommodations, potentially becoming rejected by consumers due to a lack of information.

For example, assessments of the Cheesecake Factory restaurant chain indicated that "the little information presented on their website was not enough to make a patronage decision". One student observer pointed out that several negative reviews on social media revealed that persons with other disabilities were apparently not accounted for:

One person claimed that their wheelchair could not fit into the handicapped restroom, while another person claimed that they could not get their wheelchair through the front door, because they only had a revolving door. People who were deaf or hearing impaired reported that they had a very unpleasant experience there and it was more difficult for them than other restaurants. One customer who had poor vision reported that the restaurant is too dark at night, and that it made it impossible for them to see.

\subsection{The Impact of Technology}

In contrast, movie theaters were found to offer complex accommodations due to innovations in entertainment and movie theater technology. Theaters reported having options for hand-held closed captioning, amplification and enhancement of audio, and even narration of the action on the screen. For instance, AMC offers assistive listening devices (ALDs) plus "CaptiView", a per- 
sonal closed captioning device that can be attached to a mounted cup holder as indicated in the AMC assistive moviegoing guide (AMC Theatres, 2018).

In addition, the student observers reported that theater managers noted that many accommodations were not listed online since they required personal discussion with staff and often advance reservations. Given the growing numbers of customers who gain movie, time, and ticket information online, providing full online information is a convenient opportunity to communicate welcome to persons with disabilities. In addition, AMC also reported offering "sensory friendly films" at specific times, welcoming persons with autism to comfortably get up, move about, and "dance, walk, shout, or sing". This specific option confronts the isolation of the medical model approach by offering an innovative approach that includes persons whose disabilities may manifest in less conventional behaviors.

\subsection{Informal Efforts to Provide Accessibility}

As might be anticipated, small local venues were found to made informal yet effective efforts to provide access, such as reading menus to customers who were blind and using informal hand gestures to persons who could not hear. While such efforts do not conform to typical formal accessibility laws, the reports indicated that customers were quite satisfied with the accommodative service although the information was not available to those attempting to prescreen in advance.

For instance, one student reviewed a local city's public library where she was employed. She reported a lack of online information such that:

A person with a disability would have no idea what to expect from the library based on the website. A phone call to the library was useful in clearing up questions and would be enough to reassure me that the library is handicap accessible. Based on my experience working at the library I know that there are several limitations including one bathroom without wall rails, books that are out of reach, and poor lighting in certain areas. Also, there are aisles that would be difficult for a person using a wheelchair or walking aid to navigate due to books and tables.

Finally, some venues appeared to have made no effort in communicating their accommodations to potential patrons. Information was totally absent from some globallyprominent restaurant chains as seen in Table 1 below that provides "examples of information omissions". Others had incomplete information or according to the student observers, employees who were not trained to discuss access questions. For instance, employees reported not being certain whether service animals were allowed. In discussing a small local restaurant, one observer commented that "after reviewing their web and social media outlets I was disappointed to learn they do not do a good job explaining they are wheelchair accessible".

\subsection{Variations in Publicly-Available Accessibility Information}

The observations collected in this study offer preliminary evidence that publicly-available accessibility information varies widely among public venues that consumers may want to patronize. Particularly troublesome are businesses that comply with all/some accessibility guidelines, yet they ironically do not do a consistent job informing their customers about it. For instance, one student observer could not find complete information on TGI Fridays Restaurant online in the Northeastern United States but was able to use a UK website found at disabledgo.com to complete a pre-evaluation of this global chain. The site is simple to use with a variety of accessibility icons that enable a thorough understanding of the accessibility of a specific business.

Large national sports venues could probably be called the "gold standard" both of multi-disability accommodation and of accessibility messaging. Online accessi-

Table 1. Examples of information completeness/omissions.

\begin{tabular}{lll}
\hline Example & Venue & Situation \\
\hline 1 & $\begin{array}{l}\text { Sports stadium in major NE citie in } \\
\text { the United States }\end{array}$ & Multi-disability access, accurate information \\
\hline 2 & TGI Fridays Restaurant & $\begin{array}{l}\text { Good/fair access, incomplete accessibility information online, } \\
\text { full accessibility information on disabledgo.com }\end{array}$ \\
\hline 3 & Applebees Restaurant (2 locations) & No online accessibility information; some accommodations \\
\hline 5 & Cheesecake Factory & $\begin{array}{l}\text { Online mobility access information, complaints on Twitter by several } \\
\text { customers with disabilities }\end{array}$ \\
\hline 6 & Olive Garden (Darden) & $\begin{array}{l}\text { No online access information, spacious, helpful staff, accommodates } \\
\text { on food allergies }\end{array}$ \\
& Small local Taproom/Grill & $\begin{array}{l}\text { No online access information, employees taught to informally } \\
\text { accommodate patrons with disabilities }\end{array}$
\end{tabular}


bility guides appeared to be the standard with detailed information on various types of disabilities support by staff. The venues gave a clear impression that accessibility is a priority and that they are experienced in working with patrons in advance to plan their visit. The notion of prior planning was emphasized so that the customer and any companions would be well-prepared.

\subsection{Limitations}

Since this is an exploratory study, it is necessary to briefly discuss its limitations. The study is not representative of the full range of entertainment and restaurant venues in the tri-state area where the study was conducted. As a next step, a sample should be drawn systematically from a comprehensive listing of all businesses within specific categories in order to ensure representativeness. Additionally, observers must be required to examine all possible communications channels from telephone calls and personal visits, to websites and social media posts.

\section{Recommendations}

The present article offers a call to research specifically examining the availability of information about accessibility in built environments. It calls to question whether there are policies in place that require that information about accessibility be provided to potential patrons. Today's intense and rapidly changing communications environment is full of potential to increase message accessibility to persons with disabilities. Just as universal design principles can be implemented in designing products, stores, and venues that can be used by all, an extension to "universal communications design" can enhance message transmission for a wider number of people who have access to and can respond to information conveyed by combining several styles in order to maximize the opportunities to transmit meanings.

\subsection{Requiring Standard Formats for Accessibility Information}

The article asks whether accessibility information is available online as needed by patrons with disabilities. It raises the question to policymakers worldwide whether accessibility information should be coordinated and/or regulated so that a standard format and a verified set of disabilities needs are required to be addressed.

Since there are sets of disabilities icons, words, accommodations, and symbols that can be universally adopted, the actual use of standard formats would seem to be a straightforward outreach for various types of public venues. In addressing this suggestion, policymakers might develop and test similar information summaries to determine whether they actually add to the search process and decision-making success of persons with disabilities.

\subsection{Reimagining Consumer Communications to Include Persons with Multiple Types of Disabilities}

Persons with disabilities routinely participate in growing numbers throughout educational, business, and social contexts. Yet our study found that consumers with physical disabilities in general were better accounted for then other types of disabilities. While the sporting and movie venues displayed considerable accessibility for persons with vision, hearing, and sensory disabilities, venues such as restaurants appeared to address ADA-required accommodations primarily through mobility-based assistive aids. Our study leads to the recommendation that accessibility messaging must address the concerns and questions of persons with multiple types of disabilities so they can prepare for participation in the marketplace. This expectation should lead us to ensure that our messages, our media, and our accommodations enable inclusive communications to take place maximizing understanding, response and feedback.

Future study is needed that identifies the exact information, its format, and the options that require advance notice. Disabledgo.com provides a useful starting place by considering the standard system of icons used in representing desired venues. According to the website, the icons and definitions were developed from information suggested by actual persons with disabilities. In addition, venues that provide online access to real-time assistance can examine whether online "chats" are provided in usable formats for persons with various communications abilities.

\subsection{Expanding the Access/Information Typology to a Continuous and Measurable Format}

This initial study also demonstrates that the classification typology used in this study is not detailed enough to evaluate the variations in accessibility accommodations and information communication. Some specific disabilities such as those requiring special preplanned assistance may not be able to predict the full detail needed in their accommodations for each customer. Additionally, the information needed by certain consumers may vary based on the type of media typically used and its capabilities for full access. Additional academic study is needed that integrates the opinions of persons with disabilities.

\section{Conclusion}

This article reports on an exploratory study that examined the accuracy and completeness of publiclyresearchable accessibility information. As anticipated, accessibility messaging is not complete across various types of venues but instead varies based on the venue type as well as the apparent commitment to accessibility. In addition, accommodations may vary based on venuespecific assistive technology as shown in the example of movie theater technologies. Finally, businesses who 
are compliant may increase their opportunity to include consumers with disabilities by conducting an assessment of company and third-party information and identifying both gaps and opportunities to communicate a welcoming environment.

\section{Conflict of Interests}

The author declares no conflict of interests.

\section{References}

Accessible Stadia. (2003). Sports grounds and stadia guide no 1. London: The Football Stadia Improvement Fund and The Football Licensing Authority. Retrieved from www.safetyatsportsgrounds.org.uk/ sites/default/files/publications/accessible-stadia.pdf

AMC Theatres. (2018). Assistive moviegoing guide. AMC Theatres. Retrieved from www.amctheatres.com/ assistive-moviegoing

Baker, S. M. (2006). Consumer normalcy: Understanding the value of shopping through narratives of consumers with visual impairments. Journal of Retailing, 82(1), 37-50.

Baker, S. M., Gentry, J. W., \& Rittenburg, T. L. (2005). Building understanding of the domain of consumer vulnerability. Journal of Macromarketing, 25(2), 128-139.

Baker, S. M., Holland, J., \& Kaufman-Scarborough, C. (2007). How consumers with disabilities perceive 'welcome' in retail servicescapes: A critical incident study. Journal of Services Marketing, 21(3), 160-173.

Baumeister, R. F., DeWall, C. N., Ciarocco, N. J., \& Twenge, J. M. (2005). Social exclusion impairs self-regulation. Journal of Personality and Social Psychology, 88(4), 589-604.

Bettman, J. R. (1979). An information processing theory of consumer choice. Boston, MA: Addison Wesley.

Bettman, J. R., Luce, M. F., \& Payne, J. W. (1998). Constructive consumer choice processes. Journal of Consumer Research, 25(3), 187-217.

Betts, K., Welsh, B., Pruitt, C., Dietrich, G., Watson, T., Trevino, J., \& Coombs, N. (2013). Understanding disabilities \& online student success. Journal of Asynchronous Learning Networks, 17(3), 15-48.

Brennan, J. (2013). ADA national network disability law handbook. Houston, TX: Southwest ADA Center. Retrieved from adata.org/publication/disability-lawhandbook\#PublicAccommodationsandtheADA

Bromley, R. D. F., \& Thomas, C. J. (1993). The retail revolution, the carless shopper, and disadvantage. Transactions of the Institutes of British Geographers, 18(2), 222-236.

Chouinard, V. (1997). Making space for disabling differences: Challenging ableist geographies. Environment and Planning D: Society and Space, 15(4), 379-387.

Davis, J. (2003). The accessibility divide: The visuallyimpaired and access to online news. Journal of Broad- casting and Electronic Media, 47(3), 474-481.

Friedman, D. (2016). Disabled foodie David Friedman explores accessible restaurants across the U.S. Wheel-Life. Retrieved from www.wheel-lifeWh.org/ disabled-foodie-david-friedman-explores-accessiblerestaurants-across-the-u-s

Goffman, E. (1963). Stigma: Notes on the management of spoiled identity. New York, NY: Simon \& Schuster.

Imrie, R. (1999). The body, disability and Le Corbusier's conception of the radiant environment. In R. Butler \& H. Parr (Eds.), Mind and body spaces: Geographies of illness, impairments and disability (pp. 25-45). New York, NY: Routledge.

Johnson, R. D., \& Levin, I. P. (1985). More than meets the eye: The effect of missing information on purchase evaluations. Journal of Consumer Research, 12, 169-177.

Kaufman-Scarborough, C. (2015). Social exclusion: A perspective on consumers with disabilities. In S. Dunnett, K. Hamilton, \& M. Piacentini (Eds.), Vulnerable consumers: Conditions, contexts, and characteristics (pp. 157-169). New York, NY: Routledge Critical Marketing Series.

Kaufman-Scarborough, C., \& Childers, T. L. (2009). Understanding markets as online public places: Insights from consumers with visual impairments. Journal of Public Policy \& Marketing, 28(1), 16-28.

Llewellyn, A., \& Hogan, K. (2000). The use and abuse of models of disability. Disability and Society, 15(1), 157-165.

Oliver, M. (1990). The politics of disablement: A sociological approach. New York, NY: St. Martin's Press.

Paar, H., \& Butler, R. (1999). New geographies of illness, impairment and disability. In R. Butler \& H. Parr (Eds.), Mind and body spaces: Geographies of illness, impairments and disability (pp. 1-24). New York, NY: Routledge.

Ritchie, H., \& Blanck, P. (2003). The promise of the internet for disability: A study of online services and website accessibility at centers for independent living. Behavioral Sciences and the Law, 21, 5-26.

Schaefer, K. (2003). E-Space inclusion: A case for the Americans with Disabilities Act in cyberspace. Journal of Public Policy \& Marketing, 22, 223-227.

Shakespeare, T. (1993). Disabled people's self organisation: A new social movement? Disability, Handicap, and Society, 8(3), 249-264.

Shakespeare, T. (2013). The social model of disability. In L. J. Davis (Ed.), The disability studies reader (4th ed., pp. 214-221). New York, NY: Routledge.

Shakespeare, T., \& Watson, N. (2001). The social model of disability: An outdated ideology? In S. Barnarrt \& B. M. Altman (Eds.), Exploring theories and expanding methodologies: Where we are and where do we need to go? (pp. 9-28). Amsterdam: JAI.

Swain, J., \& French, S. (2000). Towards an affirmation model of disability. Disability \& Society, 15(4), 569-582. 
United Nations. (2018). Convention of the rights of persons with disabilities. U.S. International Council on Disabilities. Retrieved from usicd.org/index.cfm/ crpd

Vierstra, C. V., Rumrill, P. D., Koch, L. C., \& McMahon, B. T. (2007). Multiple chemical sensitivity and workplace discrimination: The national EEOC ADA research project. Work, 28(4), 391-402.

Wan, E. W., Xu, J., \& Ding, Y. (2014). To be or not to be unique? The effect of social exclusion on consumer choice. Journal of Consumer Research, 40(6), 1109-1122.

WEBAIM. (2018). Using JAWS to evaluate web accessibility (job access with speech). WEBAIM. Retrieved from webaim.org/articles/jaws

Williams, K. D., \& Nida, S. A. (2011). Ostracism: Consequences and coping. Current Directions in Psychological Science, 20(2), 71-75.

\section{About the Author}

Carol Kaufman-Scarborough is a Professor of Marketing and the Director of the RSBC Business Leader Development Program. Much of her academic work investigates the marketing, retail, and legal aspects of accessibility for shoppers with disabilities. Her studies have included shopping access by persons with mobility disabilities, online access for persons with visual impairments, and in-store experiences of persons with cognitive impairments. She has presented various professional and academic seminars on the effectiveness of the Americans with Disabilities Act and has been active in disabilities access both at Rutgers and within the community. 